\title{
REVIEW ON THE CONSUMERS' RESPONSE TO THE COVID-19 CRISIS IN LATVIA
}

\author{
Dina Bite ${ }^{1}$, assoc.prof., Dr.sc.soc.; Zenija Kruzmetra², assoc.prof., Dr.geogr. \\ 1, 2 Latvia University of Life Sciences and Technologies, Faculty of Economics and Social \\ Development, Institute of Social Sciences and Humanities
}

\begin{abstract}
The regulations for restricting the Covid-19 virus set by the Latvian government, which entered into force on March 13, 2020, caused significant changes in the operation of outlets and consumer behavior. At the onset of the emergency, Latvia, like many parts of the world, experienced uncoordinated collective behavior that could potentially lead to significant changes in food supply chains.

Therefore, one of the research directions of The National Research Program project "Towards the Post-pandemic Recovery: Economic, Political and Legal Framework for the Preservation of Latvia's Growth Potential and Increasing Competitiveness" (recovery-LV) (2020) was to find out how the Covid-19 crisis Restrictions have changed buyers' habits towards buying and consuming food. The article summarizes and analyses the research results of the content analysis, semi-structured interviews and survey conducted within the project. An analysis of the results shows that, as a result of the crisis, consumers are less likely to visit outlets, cook more often at home and choose more locally sourced food. It was concluded that the consumer agitation regarding the purchase of food products in 2020 was short-lived, which later returned to the usual limits of the habits of various socio-demographic groups of the population.
\end{abstract}

Key words: consumers ' behavior; collective behavior; Covid-19 restrictions; food chains.

JEL code: P36, D12.

\section{Introduction}

The novelty and topicality of the study has been related to the study of consumer behavior in Latvia since March 13, 2020, when an emergency situation was established in the country with the aim to limit the spread of Covid-19. With the onset of various restrictions, consumer behavior changed dramatically and could develop in unpredictable directions. In the context of the theory of collective behavior, the restrictions introduced in March 2020 shook the order, creating insecurity and forcing citizens to act in conditions of high uncertainty. Restrictions directly affected food retailers through the introduction of hygiene requirements at trade areas, but the behavior of consumers was also influenced by the shift to remote working and online training, closed national borders and other factors. Crisis situations to some extent challenge existing habits and force to reconsider them. Therefore, the aim of this article is to look at relative short-term ( 2 weeks after the declaration of an emergency) and long-term ( 6 months after the declaration of an emergency) changes in consumer behavior regarding the purchase and consumption of food. The tasks of the research include the analysis of the results of theoretical literature and other similar research, the analysis of the results of content analysis and the survey of the Latvian population. Given the characteristics of the consumer society, it can be hypothetically assumed that the constraints of the Covid-19 crisis led to significant changes in the short term, but then returned to normal levels. The delimitations of the study are related to the fact that the results of the population survey on exactly such questionnaire questions before the crisis are not available. However, these limitations can be reduced by triangulation methods, namely, comparison with other similar studies in Latvia and abroad, as well as the use of different data acquisition methods.

The research methodology included a qualitative content analysis and a representative survey of the Latvian population. In July-September 2020, an analysis of publicly available sources of information was performed, including research results, expert opinions, statistics on consumer behavior during the Covid-19 crisis. Based on the results of the content analysis, 14 questionnaire questions were developed on consumer behavior in relation to the purchase and consumption of food. The survey was conducted by the research 
centre SKDS in November 2020. The sample size was 1013 respondents aged 18 to 75 years. In addition, 8 semi-structured interviews were conducted with various actors in the food chain (representatives of retail stores, fruit and vegetable growers, meat growers' associations).

The data analysis is structured according to the questionnaire, describing the main trends and, as far as possible, analysing the differences between demographic groups. The Kendall correlation test was made in order to determine possible correlations among 14 possible bahaviors. The results of content analysis and the results of semi-structured interviews were also used to explain the results of the survey.

\section{Theoretical issues of consumers`behaviour}

A customer is defined as a person who identifies his/her need or desire, buys and uses the product or product in question. Customer behavior is defined as an important and ongoing decision-making process in the selection, purchase, use and evaluation of goods and services. In general, consumer behavior is aimed at increasing their satisfaction with the purchase and use of certain goods and services (Mehta et al., 2020). The needs and desires of customers, as well as their behavior are influenced by various internal and external factors, such as the popularity of a product, marketing activities, purchasing power of the population, seasonality, etc.

The restrictions caused by Covid-19 are an unprecedented and extraordinary case that changed customers' behavior. As sociologists note, the Covid-19 situation evokes associations with the following keywords of social theory: risk, fear, panic, crisis, trust, which manifested themselves in one way or another in customer behavior (Ward, 2020). Sociological interpretations of a pandemic touch on concepts such as fear, explanation and moralization, as well as recommended action (Monaghan, 2020), which applies not only to food purchases but to all areas of life. Namely, in times of uncertainty, the population develops fear and insecurity, which accordingly requires explanation and guidelines for action.

To theoretically analyse the topic of this study, sociological theories that explain crowd behavior and the system's ability to self-regulate were selected. Namely, the theory of collective behavior developed by the US sociologist Herbert Blumer describes the breakdown of important symbols of interaction or routine actions (in this case - traditional trade practices and customer behavior), which causes unpredictable and possibly uncontrollable behavior of individuals. As a result, individuals may experience new impulses or dispositions of action that the relevant social system is unable to ensure. Individuals experience an alarm, anxiety that leads to erratic, accidental, uncoordinated behavior. During the so-called circular reaction, certain forms of behavior can spread and become uncontrollable. Collective behavior or acting crowd is formed as a result of five gradual steps: 1) exciting event, which serves as a stimulus for further reactions, 2) milling behavior, which breaks down the boundaries between individuals, 3) emergence of a common object of attention, which gives purpose to individual behavior, 4) fostering of common impulses, 5) elementary collective behavior. Through collective excitement and social contagion, individuals "infect" each other with certain forms of behavior that can be at least spontaneous and atypical, as well as violent and destructive (McPhail, 2005).

In Latvia, the crowd's reaction to trade restrictions was caused by the announcement of the Government of the Republic of Latvia on the declaration of an emergency situation from March 13, 2020. With growing lack of knowledge and uncertainty, residents rushed to stores and bought basic necessities, as well as goods with a long shelf life. Despite information in the mass media that it is not desirable to crowd the trade areas and that the goods will be delivered in sufficient quantity and time, the behavior of buyers was uncontrollable. The government's announcement of restrictions on trade areas confused shoppers, which, despite the potential threat of illness, led to increased shopping among fears of store closures, leading to 
a $7.1 \%$ month-on-month increase in food consumption in March (Ministry of Finance, 2020). There was a shortage of cereal products in the shops, especially buckwheat, which was reported in the mass media and caused fear and the next reaction of the crowd among the population.

As can be seen, the usual behavior of customers was significantly influenced by uncertainty and fear of the future, but the reaction of the crowd is only one explanation for the situation. Given the fact that citizens acted independently and autonomously, without any particular reaction to formal statements by officials, it can be considered as a self-regulatory and self-reproducing system that makes autonomous decisions. This aspect of customer behavior is explained by Niklas Luhman's concept of autopoiesis in the context of systems theory. According to this concept, society is an abstract, self-regulating and selfsustaining system that is very complex in today's world and does not follow predictable order. Society as such functions independently of institutional processes, values, with an emphasis on communication in the system and subsystems (Dillon, 2020). If a company is considered to be an operationally closed, autonomous communication system, then processes and situations that cannot be managed or controlled must be taken into account. In some cases, it operates to some extent independently of government decisions or formal restrictions, maintaining its internal logic. It is this aspect that makes the analysis of consumer behavior binding, as the effects of the crisis are not in principle predictable.

\section{Common trends in consumers' behaviour during Covid-19 crisis}

Looking at the latest publications on the impact of the Covid-19 crisis in different countries, it can be concluded that the overall situation in 2020 was quite similar. Restrictions in connection with Covid-19, which began in China on January 23, 2020, gradually covered other countries, and consumer behavior can be assessed as replicated ( $L i$ et al., 2020). For example, in describing the situation in Canada, J. H. Hobbs notes that society was characterized by short-term self-perpetuating panic among shoppers and fears of significant disruptions in food supply chains. This led to increased purchases of cereals, frozen products, hygiene products and water, which in turn led to higher prices for the products concerned. Changes in food supply chains also led to the stoppage of the so-called HoReCa sector, restrictions on gatherings, and the transition to home cooking (Hobbs, 2020). For their part, US researchers note consumer concerns about the epidemiological safety of food and the consequent shift to local food purchases (McFadden et al., 2020). Elsewhere in the world, food consumption in some product groups also increased in March 2020, for example, consumption of frozen products in France increased by $63 \%$ year-on-year and consumption of packaged foods in Germany by 56 \% (Deconinck et al., 2021). According to a survey conducted by the International Food Information Council in early April 2020, it is reported that only $11 \%$ of consumers did not change their shopping habits and $19 \%$ did not change their eating habits as a result of the Covid-19 crisis (Impact on Food ..., 2020). At the same time, it is acknowledged that the panic in food purchases is over and long-term shopping habits need to be assessed now (Roe et al., 2020).

Among the projected long-term changes in the functioning of food supply chains and consumer behavior, experts note a possible decline in household incomes, online shopping and shoppers' orientation towards local foods (Hobbs, 2020; Li et al., 2020). Long-term risks relate to social security, well-being, which can lead to poverty and greater isolation of certain marginalized groups (Deconinck et al., 2020).

Besides Covid-19 crisis, more modern approaches concerning food supply chains appear. For instance, they turn attention to 1 ) circular food supply chains trying to reduce food waste (Despoudi, Dora, 2020), 2) promoting a holistic approach to supply chain risk management (Shima, 2020), 3) ethical consumerism and its consequences (Umar, Wilson, Heil, 2017), 4) IT in agri-food food chains, green logistics, products traceability etc. (Iakovou et al. 2015). 


\section{Research results and discussion}

The total results of the research consist of 3 parts: content analysis, population survey and interview analysis results.

Qualitative content analysis included analysis of publicly available information sources - statistical data, research results of various companies (mainly trade, but also production) and organizations, opinions of specialists and experts (for example, SIA "Maxima Latvija" study on Latvian shopping habits, JSC "Poultry factory Kekava" in cooperation with "Snapshots" on the impact of the emergency situation on the eating and food purchasing habits of the Latvian population, Covid-19 barometer survey conducted by the research company "Kantar"). Given the constraints of the crisis, it was important to analyse the purchasing structure, consumer activity in order to plan marketing activities and meet customer demand, as well as other consumption-related changes.

The analysis of publicly available data shows that it was easiest for shoppers in supermarkets to comply with the established social distance and other restrictions. For small shops, it was difficult and even impossible to implement the requirements of social exclusion during the Covid-19 restrictions. The change in consumer habits in shops is characterized by features such as an increase in demand for goods with a longer shelf life, such as flour which was bought twice as much, peas, pasta and various fruits. Demand for vegan products continues to grow during the pandemic, with sales of vegan pastries more than eightfold. Due to the large number of orders, new online stores have opened, the existing ones have also opened new delivery times due to increased demand - groceries can be ordered at midnight as well. Delivery took up to four days, but due to the influx of customers, the available time is not always convenient, sometimes additional delivery times were opened throughout the day. The volume of purchases in one purchase has increased; the average shopping basket weighed 25 kilograms before the crisis, but now - $40 \mathrm{~kg}$. In Covid-19 conditions, the demand for the supply of farmers' market products by ordering them online and receiving them at home or at the place of trade has also increased.

Data from internal surveys of retailers show that after the introduction of the state of emergency due to Covid-19, the most important criteria for more than a third of customers in the choice of stores became store cleanliness and Covid-19 precautions. More often than before, buyers chose a store according to the criterion "convenient shopping in the store" (wide aisles, conveniently located product sections). On the other hand, the criterion "on the way to / from work / educational institution" has decreased the most, because, taking into account the observance of self-isolation and work from home, it was no longer relevant for a part of the population. The data also show that after the introduction of the state of emergency in the country, four out of five shoppers started visiting stores less often, and a third admitted that the size of their purchases has increased.

The results of the study show that $3 / 4$ of the Latvian population has changed their food purchasing habits due to the Covid-19 pandemic, but $1 / 4$ admit that they plan to maintain the acquired new food purchasing habits in the long run. When reviewing daily habits before an emergency, $2 / 3$ of shoppers admit that they have changed their current shopping strategy - most often they have reduced the number of store visits, choose their shopping time more carefully and have significantly changed the composition of the food basket. It can be seen that the dynamics of purchasing products with a longer shelf life has increased; the share of finished frozen products in shopping baskets has increased. The results of the study suggest that changes in consumer behavior will have a long-term impact on the food industry, the variety of products supplied, which is closely linked to new needs and not only the growing need, but also the desire to cook more and more at home. The results of these studies are not applicable to the whole population; however, 
they indicate the main trends of change, which is also confirmed by the survey data. Companies acknowledge that they are able to meet orders for certain products in part, for example, the demand for canned food has increased 15 times during an emergency, and this can be observed both in the domestic and foreign markets.

The impact of remote work on changes in the daily habits of the population is also indicated. In the past, the origin of goods was an important factor, mainly for consumers with an understanding of the principles of sustainable development, but now it is becoming more relevant for others: consumers around the world are more supportive of locally sourced products. Also, in Latvia, since March 12, 2020, when the state of emergency was declared for the first time in the country, the number of people who prefer the goods and services of Latvian companies has significantly increased. In addition, one in four is considering less frequent orders from the US and China. According to expert estimates, the habits of the Latvian population regarding the purchase of goods from Europe will remain approximately the same as before. More than half of people around the world and a little more than half in Latvia claim to eat healthier and try new recipes. However, only in the long run will it be possible to conclude whether these strategies for overcoming new conditions will turn into regular habits, as the constraints of general isolation have gradually been relaxed and people's daily lives are changing with it. There are three major changes in people's behavior around the world that will continue after the pandemic, and consumer goods and brands will have to adapt. Localism is becoming the general movement. For consumers who are aware of sustainability, brand sourcing and production strategies are an important factor. Now it is becoming relevant for a large number of other buyers.

The results of the survey on the change of shopping and eating habits of the population are shown in Fig. 1. 
I am more interested in products with a longer shelf life

I eat healthier and pay more attention to a healthy diet

I use the opportunity to order food / groceries at home more often

I am happy to choose finished products / dishes available in supermarkets

More often I cook at home, instead of choosing to visit different catering establishments

Foods that are not basic necessities (treats, snacks, sweets), I buy less

My eating habits have changed, reducing or increasing the consumption of a certain group of products

I visit shopping places less often and plan my purchases more

I shop more often in small stores than in supermarket chains

I use the opportunity to shop in small markets more often

I buy more often directly from the manufacturer than at retail outlets

I use shopping online / home delivery more

When buying food, I prefer local products grown/ made in Latvia

I have changed the places where I usually buy food

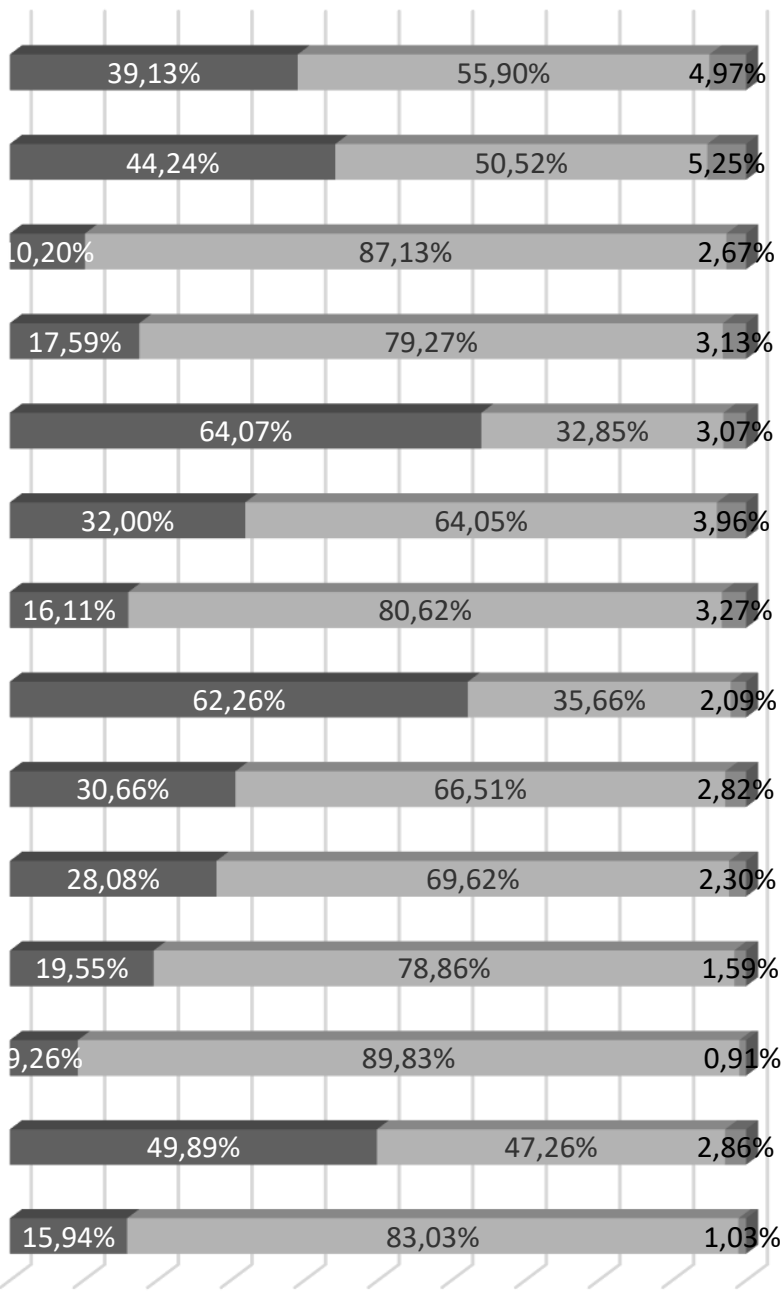

$\begin{array}{llllllllllllllll}0 & 0 & 10 \% & 20 \% & 30 \% & 40 \% & 50 \% & 60 \% & 70 \% & 80 \% & 90 \% & 100 \%\end{array}$

- Agree Disagree Hard to say/ NA

\section{Source: author's calculations based on survey results $(n=1013)$}

\section{Fig. 1. Changes in shopping and eating habits of the population (\%)}

Changes in shopping habits. Of the 1013 respondents, only $15.9 \%$ have acknowledged the change in trade places where food is usually purchased, while $83.0 \%$ of respondents have continued to buy food in their usual places of sale. Overall, $62 \%$ of respondents have visited shopping places less often and planned their purchases more. Those respondents also tend to cook more often at home (Kendall test 0.410). A significant number of respondents (62.3\%) admitted that they visit shopping places much less often and plan their purchases more carefully. As residents visit sales outlets less often, it is natural that buyers (39.1\%) are more interested in products with a longer shelf life. One third of respondents (30.7\%) more often shop in small stores than in supermarket chains, and $28.1 \%$ of respondents more often use the opportunity to shop in small markets. The Kendall test reveals relatively high correlation between shopping in small markets and shopping directly from the manufacturer $(0.443)$, as well as between shopping in small shops and small markets $(0.423)$. In both cases, they are most often respondents living in Kurzeme and Vidzeme regions. However, the majority of respondents prefer supermarket chains $(69.3 \%)$ and large markets $(69.6 \%)$. Half of the respondents have given preference to products manufactured in Latvia when purchasing food products. Overall, this shows that a significant number of people have changed their shopping strategy to adapt to the new situation. The lowest number of 
affirmative answers in the survey is about buying food in online stores (9.3\%) and ordering food (10.2 \%), but here it should be taken into account that before the emergency, online shopping was even lower. However, according to the Kendall correlation test, respondents who are keen to ordering the food at home, also, more often shop through the internet (0.382).

Changes in eating habits. Although the overall results of the survey do not show a high percentage of the population who agree with the statement about the change of eating habits (16.1\%), there are several positive trends. $32 \%$ of respondents admit that they buy less non-essential products, i.e., treats, snacks, sweets. There could be a twofold explanation: firstly, people pay more attention to food quality and health, and secondly, it could be related to the decline in income in times of crisis in part of society. $44.2 \%$ of respondents show a very positive trend, acknowledging that they eat healthier, paying more attention to a healthy diet. According to the Kendall test, there is moderate correlation between the statements about eating healthier food and preferring shopping of local products (0.324). It means that respondents associate local food production with the healthy food. Also cooking at home means healthier food for the respondents (Kendall test - 0.394). More frequent cooking at home could also promote healthy eating habits. $64.1 \%$ of respondents emphasize that they more often cook at home than visit various catering establishments, which shows that this is the dominant trend. Only $17.6 \%$ of respondents are happy to choose finished products/dishes available in supermarkets. Regarding various changes in their habits, the most active were the residents with higher education, middle income, with at least 3 people in the household, Latvians, as well as managers of different levels. Residents aged 55-75 and respondents with higher education have relatively more often chosen products made in Latvia, while residents aged 18-34 have noted online shopping more often. Shops are relatively less visited and seniors limit their spending.

Age/gender-specific habits (e.g., women's tendency to lead a healthy lifestyle, young men's habits of eating out or ordering food at home, etc.) should also be taken into account, as well as factors influencing consumer choice apart from crisis constraints. For example, differences in store network infrastructure and available products in different regions of Latvia. In general, the results of the survey are in line with the trends described in the content analysis, but it is necessary to take into account how the situation will develop in the autumn of 2020 in the context of the crisis and beyond.

Interviews with various actors in the food chain mainly confirm the above-mentioned tendencies about changing customer habits (long-term storage of goods lasted all spring and summer, Latvian products were mostly preferred, certain product groups were purchased more intensively, such as sweets, alcohol). Retailers confirmed the increase in profits in small stores due to the growing demand for various goods. Companies with long experience had no problem building up product stocks or responding to customer demand for certain product groups. Retailers do not point to specific problems with food supply. Several businesses ordered certain products in bulk before the official start of the crisis. Latvian stores also benefited from the closure of the border with Lithuania, where Latvians often go shopping due to lower prices. The increase in the profits of small shops was facilitated by remote working, which led locals to shop at nearby shops.

The social "profile" of buyers has also changed - they are mostly people with good incomes, working in well paid places, who prefer product quality over quantity. For this reason, the range of goods was expanded during the crisis. Some innovations were also introduced in small stores - to reduce physical contact, ordering goods through WhatsApp was introduced, when the buyer sends a list of goods, the sellers pack everything and the buyer picks up the goods. As a result, time could be saved and there was no intensive contact. The advantage of small shops is flexibility in choosing and ordering goods. In general, there have 
been no problems in the supply of goods; manufacturers and traders are accustomed to working in changing conditions; therefore, no particular effect of Covid-19 is noted. To a certain extent, the representatives of supermarkets express the opposite opinion, noting that already in January 2020 the income of the population decreased and they started to save money. Supermarket revenues fell due to the fact that people cooked more at home, planned spending more carefully, and bought the cheapest products. Until then, supermarket chains followed buyers' choices, for example by supplying quality vegetables, etc., afterwards measures had to be put in place to 'keep' buyers, for example by freezing prices. This situation was to some extent caused by the situation of remote work, as a result of which there was a decrease in trade in Riga, but an increase in other regions of Latvia.

Interviews with fruit and vegetable growers indicate that although many shops are not loyal to local products, at the same time there is a growing public desire to buy local fruits and berries. There has been a great deal of interest in berry and fruit picking in this summer of Covid-19, which indicates that there is a desire in the public to consume local fruit and berries. Consumers have been found to be more likely to buy longer-lasting products under Covid-19 risk conditions, but at the same time they have started to buy healthier products, according to a survey. According to press reports, fresh vegetables are one of the most sought-after products during the pandemic. However, it is pointed out that there is a decline in purchasing power, especially further from Riga, so more expensive fruits and berries, such as blueberries, are bought less.

Interviews with meat producers and meat processors also recorded a change in consumer habits during the Covid-19 crisis. Representatives of the Latvian Pig Breeders' Association confirmed that with the onset of the Covid crisis, the turnover/consumption of pork increased significantly, as people cooked more at home compared to the pre-crisis period. During the crisis, the shift to short food chains 'from farm to fork' increased, and it was also a very good support for rural families. Changing consumer habits allow home producers to slowly grow into normal businesses.

Representatives of the Beef Cattle Breeders' Association, on the other hand, said that due to Covid restrictions, households spend a lot of time at home, "a big wave of appreciation of local meat is starting to appear." Local demand is growing and the buyer is beginning to appreciate quality beef. These changes are affected by both the Covid-19 crisis and the change of generations, as well as more mobile communication between buyer and seller, buyer and manufacturer, thanks to the e-environment, which became significantly more used in times of crisis.

\section{Conclusions}

1) The changes in consumers ' habits in sociology can be explained through the lens of crowd behaviour and society as a self-regulated system;

2) The results of the content analysis and the survey, and interviews reveal a number of common trends: increase of on-line shopping, prioritizing of local food and slight changes in the food supply chains that go in line with the worldwide trends;

3) There is correlation between several behaviors - cooking at home and eating healthier, shopping in small markets and shops as well as directly from the manufacturer. It allows to conclude that the structure of the food supply chain is changing gradually.

4) Consumers in Latvia rapidly adapted to the limitations and acted accordingly to uncertainties in the market demonstrating signs of the crowd behaviour, however, in a relative long-term perspective, changes in consumers ' behaviour are more determined by socio-demographic factors and previously 
accustomed practices. Also, such determinants like available finances and infrastructure must be taken into account;

5) All in all, Covid-19 crisis has been caused the re-assessment of existing purchasing and eating habits that has it's potential to change the structure of the food supply chains.

\section{Acknowledgment}

The paper was supported by the National Research Programme "Towards the Post-pandemic Recovery: Economic, Political and Legal Framework for Preservation of Latvia's Growth Potential and Increasing Competitiveness" (recovery-LV), Project Agreement: VPP-COVID-2020/1-0010.

\section{Bibliography}

1. Deconinck, K., Avery, E., Jackson, L.A. (2020). Food Supply Chains and Covid-19: Impacts and Policy Lessons. EuroChoices, Volume 19, Issue 3, pp. 34-39.

2. Despoudi, S., Dora, M., (2020). Circular Food Supply Chains. Food Science and Technology, Volume 34, Issue 1, pp. 48-51.

3. Dillon, M. (2020). Introduction to Sociological Theory: Theorists, Concepts, and their Applicability to the Twenty-First century. 3d edition. Hoboken, NJ: John Wiley\&Sons, Ltd. p. 530.

4. FM: Aprili mazumtirdznieciba specigakais kritums pedejo 10 gadu laika (2020). Retrieved: https://www.fm.gov.lv/lv/sadalas/tautsaimniecibas_analize/tautsaimniecibas_analize/mazumtirdznieciba/62350 -fm-aprili-mazumtirdznieciba-specigakais-kritums-pedejo-10-gadu-laika Access: 25.02.2021.

5. Iakovou, E., Bochtis, D., Vlachos, D., Aidonis, D. (ed.) (2016). Supply Chain Management for Sustainable Food Networks. Chichester: John Wiley \& Sons, Ltd., pp. 311.

6. Impact on Food Purchasing, Eating Behaviors, and Perceptions of Food Safety (2020). Retrieved: https://foodinsight.org/wp-content/uploads/2020/04/COVID-19-Consumer-Research.April2020.pdf Access: 25.02.2021.

7. Hobbs, J.E. (2020). Food Supply Chains During the COVID-19 Pandemic. Canadian Journal of Agricultural Economics: Special Issue Article, Volume 68, pp. 171-176.

8. Li, J., Hallsworth, A.G., Coca-Stefaniak, J.A. (2020). Changing Grocery Shopping Behaviours Among Chinese Consumers at The Outset of the COVID-19 Outbreak. Journal of Economic and Human Geography, Volume 111, Issue 3, pp. 574-583.

9. McFadden, B.R., Malone, T., Kecinski, M., Messer, K.D. (2020). COVID-19 Induced Stigma in U.S. Consumers: Evidence and Implications. American Journal of Agricultural Economics, Volume 103, Issue 2, pp. 486-497.

10. McPhail, C. (2005). Blumer's Theory of Collective Behaviour: The Development of a Non-Symbolic Interaction Explanation. Sociological Quarterly, Volume 30, Issue 3, pp. 401-423.

11. Mehta, S., Saxena, T., Purohit, N. (2020). The New Consumer Behaviour Paradigm amid COVID-19: Permanent or Transient? Journal of Health Management. Volume 22, Issue 2, pp. 291-301.

12. Monaghan, L.F. (2020). Coronavirus (COVID-19), pandemic psychology and the fractured society: a sociological case for critique, foresight and action. Sociology of Health and Illness, Volume 42, Issue 8, pp. 1982-1995.

13. Roe, B.E., Bender, K., Qi, D. (2020). The Impact of COVID-19 on Consumer Food Waste. Applied Economic Perspectives and Policy, Volume 43, Issue 1, pp. 401-411.

14. Shima, M., (2020). Managing Food Supply Chains. Food Science and Technology, Volume 30, Issue 3, pp. 2022.

15. Umar, M., Wilson, M., Heyl, J. (2017). Food Network Resilience Against Natural Disasters: A Conceptual Framework. SAGE Open: Business and Management, Volume 7, Issue 3, pp. 1-11.

16. Ward, P.R. (2020). A Sociology of the Covid-19 Pandemic: A Commentary and Research Agenda for Sociologists. Journal of Sociology, Volume 56, Issue 4, pp. 726-735. 